\title{
Changing the Perception of Business Values in the Perspective of Environmental Sustainability
}

\author{
Mária Demjanovičová and Michal Varmus *
}

Citation: Demjanovičová, M.; Varmus, M. Changing the Perception of Business Values in the Perspective of Environmental Sustainability. Sustainability 2021, 13, 5226. https:// doi.org/10.3390/su13095226

Academic Editor: Umberto Panniello

Received: 1 April 2021

Accepted: 4 May 2021

Published: 7 May 2021

Publisher's Note: MDPI stays neutral with regard to jurisdictional claims in published maps and institutional affiliations.

Copyright: (c) 2021 by the authors. Licensee MDPI, Basel, Switzerland. This article is an open access article distributed under the terms and conditions of the Creative Commons Attribution (CC BY) license (https:// creativecommons.org/licenses/by/ $4.0 /)$.
Faculty of Management Science and Informatics, University of Žilina, 01026 Žilina, Slovakia; demjanovicovaml@gmail.com

* Correspondence: michal.varmus@fri.uniza.sk; Tel.: +421-415-137-741

\begin{abstract}
This study provides an overview of practical approaches to sustainability and its communication to the public in the business sector. The research presented in this article is focused on perceived sustainability in micro and small enterprises in Slovakia through research of business models used by these enterprises using a qualitative approach. The aim is to provide a general view on this topic and to prepare the basis for a sustainable business model composed of the values of society in micro and small businesses in Slovakia. The research consists of two phases-research in the field of business environment through personal interviews with entrepreneurs (examination of parameters: locality, waste management, ecological components, minimization of waste) and research of consumers' perceived values within the perception of environmental problems. Businesses perceive the seriousness and necessity of solving the problem. Entrepreneurs from the micro and small segments perceive the high importance of solving elements of sustainability. They mentioned the minimization of waste as the most important element, the highest value on the scale (5) was marked by up to $85 \%$ of respondents. From a customer survey, it is possible to assess that almost $86 \%$ of respondents in this case feel that global problems are affecting them personally and at the same time more than $62 \%$ of them believe that they can influence the offerings of companies through their purchases and support sustainability in the business environment.
\end{abstract}

Keywords: sustainability; perceived value of sustainability; sustainable business model; value parameters; social responsibility

\section{Introduction}

Sustainability can be approached from multiple perspectives. In this case, sustainability is being researched within the business context as the main aspect of the operation of the whole business-making system, in connection to the social and value system of the consumers. Business entities have considerable impact on the environment. They represent the supply of goods and services, bring innovations, and can affect the whole market. However, this should be done only until their activities negatively influence other stakeholder groups. There are various entities entering the system [1]. Understandably, there is the government setting the boundaries of fair trade on the market, the business entity itself with its business model, the consumer (customer) buying the products and services, as well as the environment enabling the operation of this system [2]. The environment represents the surroundings, nature, atmosphere, material, and other conditions necessary for the existence of the system.

Therefore, sustainability can be viewed from the perspective of each of these stakeholder groups. Nevertheless, a responsible approach is the one where all the other entities entering the whole system are considered [3].

Sustainability in this study is perceived as responsibility and an active approach to finding a greener alternative in the business environment. It is a matter of choosing materials that should be sustainable, as well as supply routes that should be shortened to reduce the carbon footprint. The impact of inputs will also be adequately influenced by 
sustainability elements. This is linked to the customer via the business itself. Creating a sustainable supply will thus ensure the next step for social sustainability and provide the market with a sustainable alternative to conventional products and services.

CSR is a functional basis for setting sustainability goals in capacity-unlimited business models. The principles of CSR can be applied to all business models; therefore, this concept is the starting point for the position of the theoretical foundations in this article.

From the perspective of the business and the product or service it provides, attention can be paid to whether this product is recyclable, whether it was developed and produced by a sufficiently efficient, environment-friendly process, and so on [4]. A suitable model for sustainable operation is summarized in the CSR (Corporate Social Responsibility) concept. This is a concept of responsible operation and a sustainable approach not only to materials but to the whole environment. Strand is one of the experts in this field, dealing with the CSR concept not only as a researcher but also connecting it with practice. In his studies, he successfully points out the necessity of addressing this topic via specific examples from corporations. This way, he can point out the deficiencies as well as provide a more responsible alternative and thus a solution leading to sustainability $[5,6]$.

Sustainability understood environmentally is a necessary element within the business context. It represents a new aspect in the managerial as well as the marketing perspective. Businesses do not focus only on the customer, political, social, or ethical perspective. There is another inseparable part of the business operation that needs to be addressed and considered, upon which the whole business model must be set [5]. "The so-called sustainable model's role is to analyze, manage, and communicate the generation and maintaining of the value while sustaining or regenerating natural, social, and economic possessions, going beyond the organizational goals" [7] Despite all the measures of the government and the promises made by retail chains, the state of the environment is not getting better, on the contrary, it is getting markedly worse. The climate conditions around the world underwent unprecedented changes and the statistics show that the climate crisis, loss of biodiversity, and global inequality warn about an adverse situation [8]. Businesses are not sufficiently engaged in the improvement of the global conditions and gaps occur between the statistics and reality.

A precondition for the achievement of sustainable goals is the provision of a transfer of substantial information within society. If the public gets substantial information on sustainability and its necessary application in everyday life from multiple sources, it will be possible to apply its values in the business environment as well (Figure 1). It is not possible to sell the customers a more expensive product without explaining to them what they are paying for. In the same way, it is not possible to implement the values of sustainability in a business without helping the employees identify with these values [9].

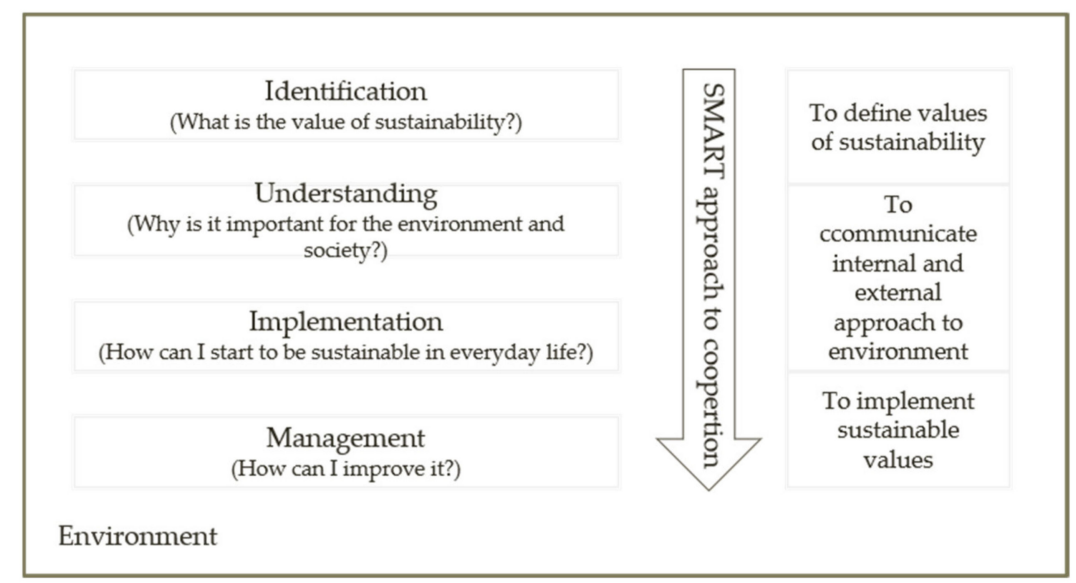

Figure 1. The process of identification with the values of sustainability [10]. 
The process of getting familiar with the value of sustainability can be applied within the public as well as in a business. The substance is the same, to identify, understand, implement, and manage. There are also cases when people understand the consequences of their unsustainable purchasing behavior, but they do not have sufficient information on the alternatives, so they stick to proven products [11]. For this reason, it is important to increase the motivation of the businesses themselves. They need to realize that they are responsible for spreading information on the value of sustainability to the customers.

\section{Materials and Methods}

\subsection{Researched Areas of Business Sustainability Values}

This article studies sustainability from the perspective of cooperation of all the stakeholders. Creating the values of sustainability in the business environment is not possible unless the environment recognizes them. For this reason, it is necessary to think about sustainability as a cycle of knowledge, understanding, and the ability to translate the values of sustainability into all the elements of the stakeholders' operation in the natural environment. Figure 2 shows the stakeholder groups and their sustainability values.

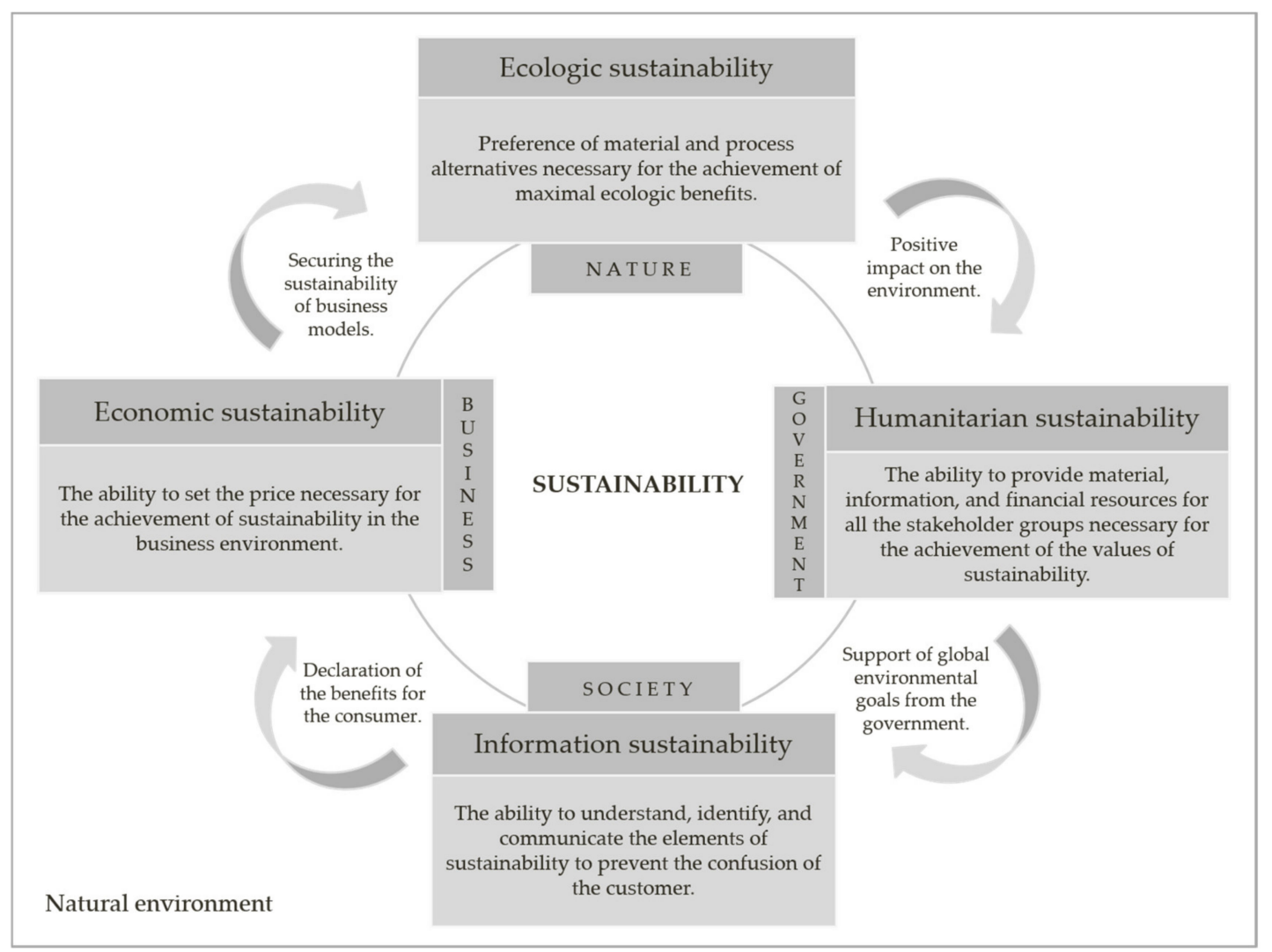

Figure 2. Studied aspects of sustainability and their mutual interconnections.

Based on the knowledge from the theoretical research, the need to address the issue and its relevance are confirmed. According to the CAS theory and the theoretical foundations, it is necessary to understand the importance of interconnection in the model $[5,6,12]$. To establish viable sustainability management, it is essential to be aware of all the stakeholders in this process.

\subsection{Research Methodology and Hypothesis}

What are the plans and reactions of local entrepreneurs regarding the elements of ecological sustainability in their business models? This research includes a survey conducted on a deliberately picked sample of 62 businesses from three segments (gastronomy, 
services, production) of the Slovak economy for this article. The businesses sectors include the restaurant sector (coffee shops, restaurants, etc.), the production sector (production of furniture, toothbrushes, etc.), and the sector of services (a wedding agency, a laser arena, transport services, etc.). This research is part of a larger project, which consists of an analysis of business models in Slovakia. For this research, a qualitative approach to the data collection was selected, personal interviews directly in the businesses. This part of the research consists of 62 interviews with entrepreneurs from local Slovak businesses. The main objective of the research was to understand how they work daily, what is their perceived value of their business models, and how they understand sustainability. After this phase, it was possible to collect data and divide them into the 3 segments of interest. These parameters were amended after the second phase of the research, which is the core of this article.

The sample of micro and small businesses was a result of a deliberate selection within the businesses in Slovakia. These were businesses with between 1 and 10 employees. They must be active, conducting business in one of the three selected segments-food companies (gastronomy), services, or production. Within the food company, cafes, bakeries, restaurants, cake shops, and businesses selling gastronomy equipment were included. The segment of services included the businesses providing services of any kind. The actual sample includes a legal consulting company, hairdresser, event agency, and a car repair shop. The production segment is represented by businesses producing furniture, construction companies, and a company producing toothbrushes.

The businesses were approached directly via email, and the selection was performed using a website providing information about businesses in Slovakia, finstat.sk [13]. These were local entrepreneurs from various regions of the Slovak Republic. The research was performed using the questionnaire technique in its online form. Generalization of this situation created the foundations for the research that opens the topic of ecological sustainability in micro and small businesses in Slovakia.

Research questions

- What is the level of awareness in this field?

- Do entrepreneurs apply elements of sustainability to their business models?

- Do customers perceive the issue of the natural environment?

- Do customers feel that their shopping behavior can affect business offerings?

Research hypothesis

Hypothesis 1 (H1). If the entrepreneur knows the parameters of the value of sustainability, then his motivation to apply them to his business model increases.

Hypothesis 2 (H2). If micro and small businesses perceive the parameters of sustainability value as important, they also apply them to their business models.

Hypothesis 3 (H3). If customers perceive the need to solve environmental problems in the business activities of companies as important, then they are looking for sustainable companies.

\subsection{Research Sample and Its Specifications}

\subsubsection{Business Research Sample}

In this part, the research was specifically focused on micro and small businesses in Slovakia. Its topic was the perception of sustainability in businesses such as whether sustainability is substantial, which elements are perceived as substantial, and which are not. The businesses included in the research are micro and small companies from Slovakia.

The research sample was selected by a random selection at finstat.sk-a database of entrepreneurs from Slovakia (Table 1). The selection parameters were the number of employees (1-10), profitability in the last 2 years, and the company sector (restaurant sector, services, production). The research sample consisted of 92 active businesses that were 
contacted via email. The research was supported by 62 business entities. The answers were collected from the businesses' CEOs or managers.

Table 1. Research sample specification—business research.

\begin{tabular}{|c|c|}
\hline Sample Specification & Parameter of the Research Sample \\
\hline The size of the research sample & 62 entrepreneurs/CEOs from micro and small companies \\
\hline Method of selection & Deliberate choice \\
\hline Selection parameters & $\begin{array}{l}\text { Minimally } 1 \text {, maximally } 10 \text { employees } \\
\text { Profit for the last two accounting periods } 0+€ \\
\text { Sector-gastronomy, production, services }\end{array}$ \\
\hline Location & Slovakia \\
\hline Duration of the survey & May 2020-November 2020 \\
\hline
\end{tabular}

\subsubsection{Consumer Research Sample}

The consumer survey was conducted online, and its sharing was electronic (Google Forms) through various communication channels, so that the survey addressed the widest possible range of respondents, given the age, level of education, or place of permanent residence. The survey ran from 3 December 2020 and lasted until 20 February 2021 (Table 2). A website was created for the communication of the given survey, which contained basic information related to the given topic, so that the potential respondent would be interested and willing to support the survey. At the same time, the information on the support website did not provide a large amount of information so as not to influence the respondents' answers. This is just a very simple introduction to issues with a motivating character. An online space under the auspices of the wordpress.com platform was used to create an information website, and it is a website owned by the author. Its operation was free for a period of one year of use. The website was named after the keyword of the research activity to motivate respondents-https:/ / tvorimehodnotu.wordpress.com/ (accessed on 15 February 2021).

Table 2. Research sample specification-consumer research.

\begin{tabular}{cc}
\hline Sample Specification & Parameter of the Research Sample \\
\hline The size of the research sample & 354 respondents \\
\hline Method of selection & Random choice \\
\hline Selection parameters & $\begin{array}{c}\text { Age } \\
\text { Region }\end{array}$ \\
\hline Location & Slovakia \\
\hline Duration of the survey & December 2020-February 2021
\end{tabular}

\section{Results}

\subsection{The Research of the Perceived Value in Slovak Local Businesses}

The outputs from these interviews are the specific parameters that explain the perceived value of each business from the perspective of its boss. From the results, four main groups for the perceived value parameters were created, consisting of 15 individual parameters. These groups of the value parameters perceived by the entrepreneurs include:

- Product (quality, bio, local),

- $\quad$ Service (interior design, additional services, staff qualifications, custom access, special accessories, supplementary program),

- Environment (waste recycling),

- Emotions (minimalization of the waste production, social business impact, eco products, atmosphere, company name) [14]. 
The parameters of the value perceived by the entrepreneurs were the basis for the next analysis. After analyzing similar studies of sustainability and sustainable business models from the environmental perspective, it was possible to compare the terms used in common practice and adjust the parameters for the main topic of the research $[15,16]$. The first research was focused on these parameters:

- Locality-prioritization of local suppliers (reducing carbon footprint),

- Waste management (recycling, separation, etc.),

- Ecological components-procurement of goods from sustainable sources,

- Minimization of waste (wasting energy, material, etc.).

\subsubsection{Prioritization of Local Suppliers (Reducing Carbon Footprint)}

The awareness in relation to this issue was at a good level for the majority of businesses. The essence of the prioritization of local suppliers is known to entrepreneurs. They also often describe this element as important from the perspective of the local market and local economy. This also represents one of the fundamentals of a circular economy. In relation to this element, the highest importance was assigned with the highest frequency in the food company (52.4\% of respondents), followed by the segment of services $(40 \%)$ and the production segment (also 32\%). The difference among the segments can be caused by the fact that in production the system of supplying can be planned more easily, and the process of supplying has a longer cycle. In comparison, the supplying process in the food company is much different and most of the products are being delivered daily.

Investigation of the relationship between the perceived importance of the parameter "prioritization of local suppliers" and the subsequent implementation of the parameter into the business model. The aim was to determine whether the variance of the boundaries of perceived importance and the subsequent application of the parameter to the model is significant. The ANOVA test using the SPSS program was used for statistical investigation (Table 3).

Table 3. ANOVA test-monitoring the performance of the parameter "preference of local suppliers" and its perceived importance.

\begin{tabular}{cccccc}
\hline Prioritization of Local Suppliers & Sum of Squares & df & Mean Square & F & Significance \\
\hline Dispersion between groups & 29.53 & 3 & 0.984 & 5079 & 0.003 \\
Within Groups & 11.241 & 58 & 0.194 & & \\
Total dispersion & 14.194 & 61 & & \\
\hline
\end{tabular}

The results confirmed the dependence of the importance of the parameter "preference of local suppliers" and its subsequent implementation into the business model of the company. To determine the magnitude of the effect (r) of this parameter, its effect is calculated using the formula:

$$
\mathrm{r}^{2}=\frac{\text { Dispersion between groups }}{\text { Total dispersion }} \rightarrow \mathrm{r}=\sqrt{ } 14.194 \rightarrow \mathrm{r}=3.77 \text { (Strong magnitude of the effect) }
$$

Individual segments of entrepreneurs compiled according to the perceived importance of the parameter "preference of local suppliers" differ statistically significantly in the implementation of the parameter in their business model, $\mathrm{F}=5079, p<1$, with a high effect of 3.77 .

\subsubsection{Procurement of Goods from Sustainable Sources}

The preference for sustainable sources is an often-discussed topic. The substitution of standard incandescent light bulbs with LED lights is being actively applied in the public sector. However, this is only one of the possible ways to contribute to sustainability. The substitution of combustion engines by hybrid or electric engines and the change of heating systems are other such ways. Conventional options are being replaced by their more 
ecological alternatives [17]. These ecological innovations are common in large businesses, but in local micro-businesses, each such investment is discussed and recalculated several times. The preference for a more ecological alternative is often financially demanding. Therefore, this element is often postponed, and entrepreneurs implement such innovation only when they are forced to do so, e.g., by the government. The highest frequency of this element was recorded for the food company again, and up to $90.5 \%$ of respondents assigned the highest importance to it within environmental sustainability. In the segment of services, the frequency was $72 \%$, and in the segment of production, this element was considered highly important by $86.4 \%$ of respondents. An interesting extreme occurred in the food company segment where one respondent perceived this element as almost unimportant. This was the case of an owner of a specialized beer shop selling craft beers from local breweries. Even though the owner is interested in sustainability, he cannot affect this element; therefore he considers it to be almost unimportant for his operation. If he does not want to lower the quality of his products, he cannot look for alternatives (for the packaging, transport, or beer cooling). Nevertheless, the fact that the owner is interested in the issues of sustainability is an important positive finding.

\subsubsection{Waste Management (Recycling, Separation, etc.)}

Recycling, separation, upcycling, and many other effective ways of waste management have been known in Slovakia since the first steps of the EU towards awareness in this field, starting in 2014 within the Europe 2020 program. A lot has changed since that time even in Slovakia. Over time, people have learned that there are many ways to work with waste. Nevertheless, the first step is waste separation. This applies to the business environment as well. The accessibility of the bins for the separated waste plays an important role in changing habits. Other steps of the government helped change the habits of entrepreneurs too since the government started to create pressure on the reduction of the waste via sanctions. Businesses started to look for an alternative. The survey's results show that this element is perceived as a fundamental step by the respondents-highly important within the topic studied. This is supported by the assignment of five points on the scale in all the segments with the frequency above $50-57 \%$ in the food company, $52 \%$ in services, and $36 \%$ in the production segment.

\subsubsection{Minimization of Wasting (Wasting Energy, Material, etc.)}

The last element does not only represent environmental sustainability but also economic efficiency. In this case, it was revealed that if the value of the element is directly favorable for the business, the level of importance of this element for the management of the business is considerable. Up to $83 \%$ of all the respondents assigned the highest value on the scale to this element.

The following graph (Figure 3) shows the perceived importance of individual parameters by segments. The most significant results can be observed with the parameters "waste minimization" and "ecological components". These are the most significant results in terms of perceived importance for all three monitored segments.

The research was also focused on the identification of the elements that are already implemented in the business models by the entrepreneurs; thus they already have actual experience with the elements from the practice. The willingness of entrepreneurs to improve within the studied topic represents an important precondition for the design of the part of the new model oriented on environmental sustainability in the business environment. Therefore, another question dealt with the entrepreneurs' plans within this field. Which of the elements are important for local businesses and which are they planning to implement in their business models? Figure 4 captures the state of the planned applications of individual elements of environmental sustainability in the business models analyzed. 


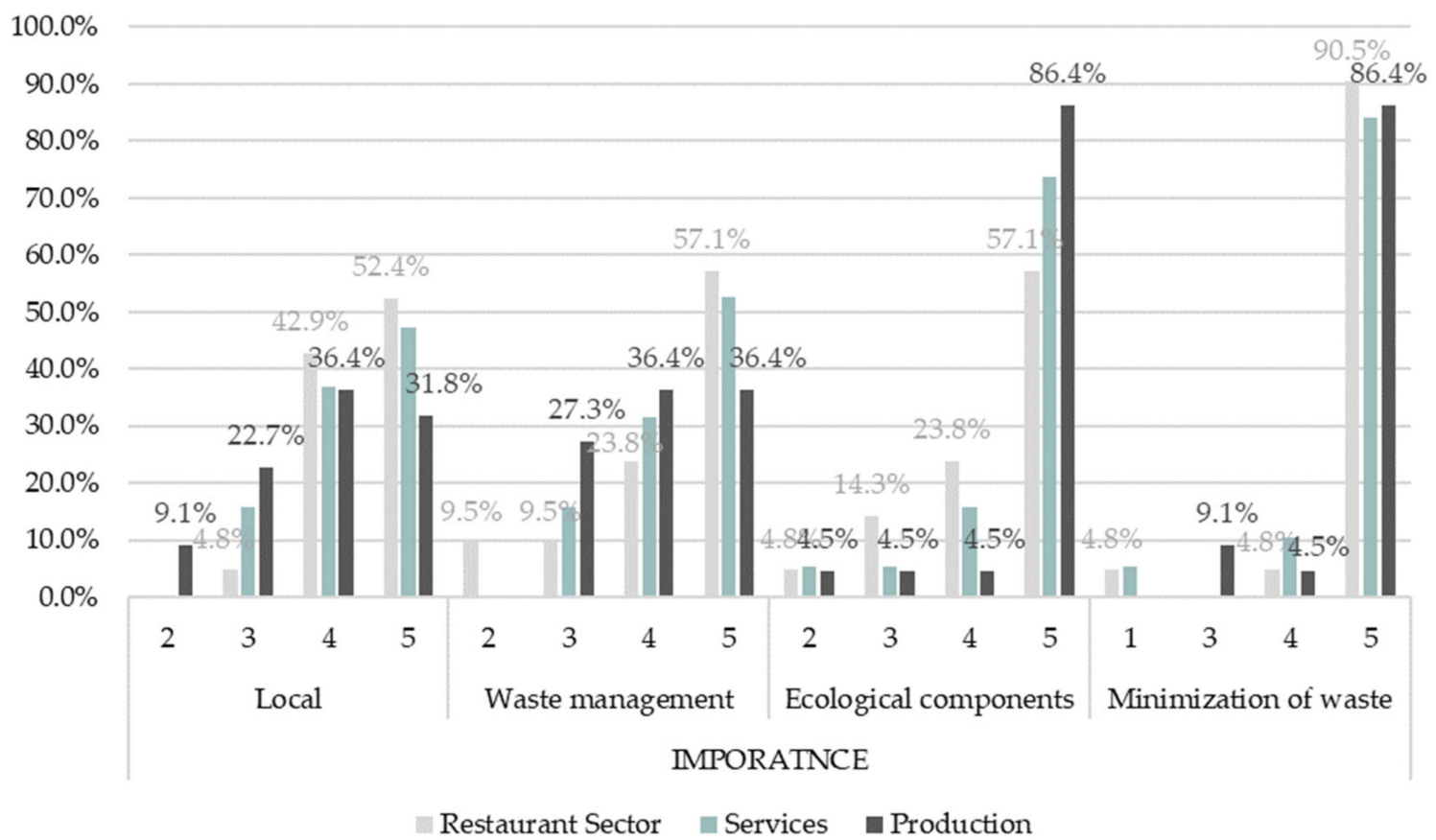

Figure 3. Perceived importance (1-5) of individual parameters according to segments.

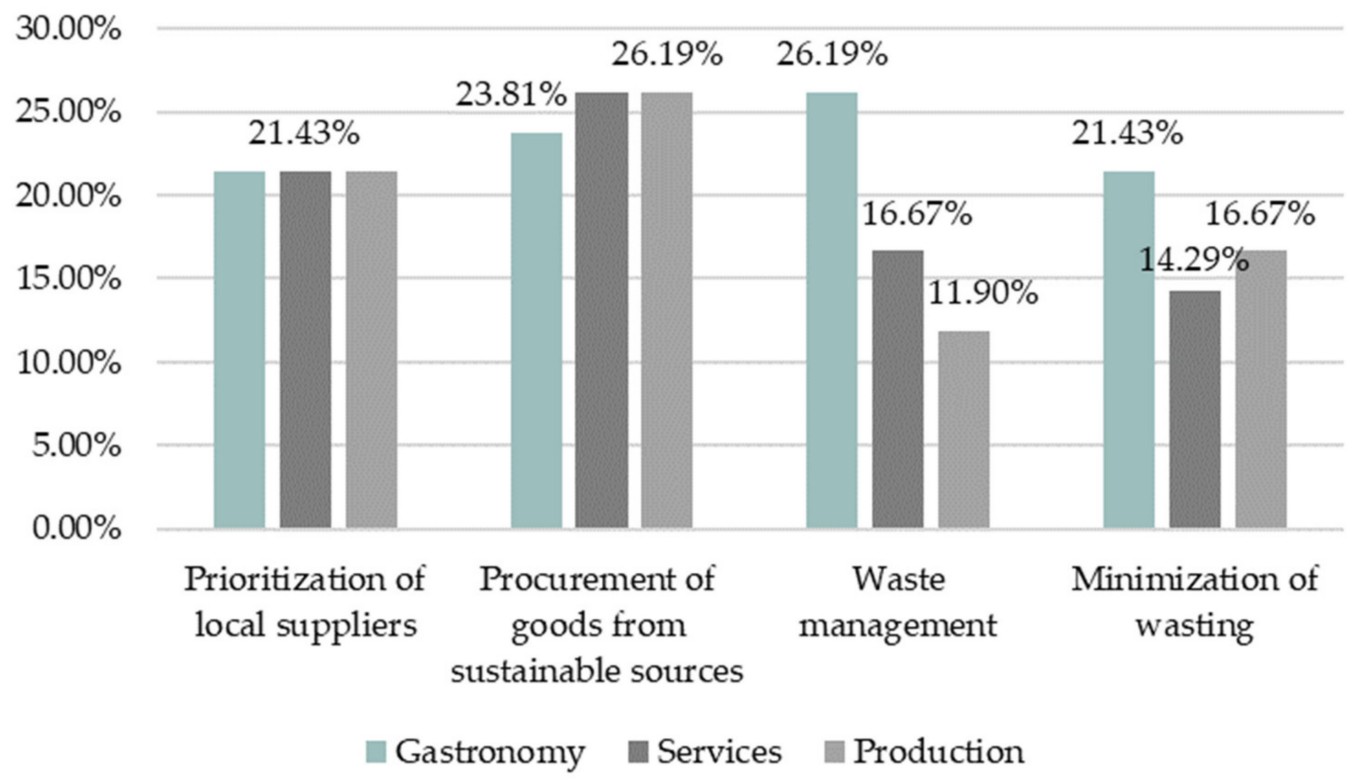

Figure 4. The planned implementation of the elements of environmental sustainability in individual segments.

The preference for procurement from sustainable sources represents an activity that is planned the most often among the respondents. This was observed even though the same element did not have such a high value of importance assigned among all the elements studied. The chart shows a considerable interest in the planning of the application of individual elements of sustainability in the business models.

Entrepreneurs from the micro and small segment perceive the high importance of solving elements of sustainability. They mentioned the minimization of waste as the most important element, for this parameter, the highest value of importance (5) was marked by up to $86 \%$ of respondents. This fact may be due to the fact that minimizing waste has a direct positive impact on the economic results of entrepreneurs. Given the issues addressed, 
the differences between the segments are interesting. The gastro segment is significantly more active in most parameters compared to production and services. In addition, it is production that lags in most cases.

A positive indicator is the fact that companies plan to apply elements of sustainability to their business models, even those that they have not identified in terms of importance as significantly important. This consequence may be because entrepreneurs identified as essential those they practice in terms of personal responsibility. Sounding fair is essential in the field of micro-business and entrepreneurs are careful how they express themselves on individual topics. Of course, these topics are also taken seriously by large companies, but in their case, the loss of one customer will not cause as significant losses as in the case of a local entrepreneur. So this fact can be perceived as the so-called maneuver to ensure that they also apply the important elements of sustainability they perceive, that is, they try. However, it is essential in the context of research that they want to improve and plan to implement activities within the elements of sustainability soon.

In the following table (Table 4), it is possible to see the percentage of answers to the question of the perceived importance of individual parameters. These are entrepreneurs who have indicated that they perceive the parameter as important and very important (indicated by 4 and 5, respectively). The table shows an overview of differences in the importance of individual parameters based on the monitored segments-gastronomy, services, and production. The highest perceived importance can be observed in the segment of gastronomy, which also appeared to be the most active in previous results. As many as $95 \%$ of respondents described the parameters "minimizing waste and prioritizing local suppliers" as very important. It is the "waste minimization" parameter that is considered to be the most important given the average percentage in responses of the highest importance. The largest variance between segments occurs in the parameter "prioritization of local suppliers", where only $68 \%$ of respondents in the production segment marked the parameter as important and very important, and in the case of the gastro segment up to $95 \%$. These results point to the maturity of the gastro segment in the given issue and its active implementation of sustainability values not only into the internal activities of the company, but also their transformation among the company's stakeholders. In any case, there is no significant difference with the other parameters. The perceived importance is at a high level and so it is possible to assess that the perception of the issue in the Slovak business environment is at a level capable of actively implementing change.

Table 4. Percentage of answers ranked 4 and 5 on a scale of importance.

\begin{tabular}{ccccc}
\hline & Gastronomy & Services & Production & Average \\
\hline Minimization of waste & $95.30 \%$ & $90.90 \%$ & $91.20 \%$ & $92.47 \%$ \\
Ecological components & $80.90 \%$ & $89.00 \%$ & $90.90 \%$ & $86.93 \%$ \\
Waste management & $80.90 \%$ & $83.00 \%$ & $72.80 \%$ & $78.90 \%$ \\
Prioritization of local suppliers & $95.30 \%$ & $85.00 \%$ & $68.20 \%$ & $82.83 \%$ \\
\hline
\end{tabular}

\subsection{The Survey of the Consumers' Perceived Value of Sustainability in Slovakia}

The results of the survey are as follows. Three hundred and fifty-four respondents participated in the survey. They were $47 \%$ male, 53\% female. Most respondents (34.8\%) are in the age range of 24-29 years. Subsequently, 28.4\% are in the age range of 30-39 years, $23.2 \%$ in the age range of $8-23$ years, $10.3 \%$ in the age range of $40-55$ years, and the rest are older respondents. The locality is dominated by the Žilina and Bratislava regions, Slovak Republic.

\subsubsection{Perceived Importance of Value Parameters}

In the given graph (Figure 5), we can see the individual examined parameters of the value and the percentage evaluation of the perceived importance by the respondents. The color scale distinguishes the perceived importance from 1 to 5 . Of course, the highest value represents the highest level of importance of the parameter. At levels 4 and 5, the 
most significant result was for the parameter of waste management, $23.16 \%$ and $66.95 \%$ of respondents in this case stated levels 4 and 5, respectively. The second parameter is the minimization of waste $(27.97 \%$ and $61.30 \%)$. The third most important parameter is the ecological safety of materials with $33.33 \%$ and $48.31 \%$ of respondents giving it a rating of 4 and 5, respectively.

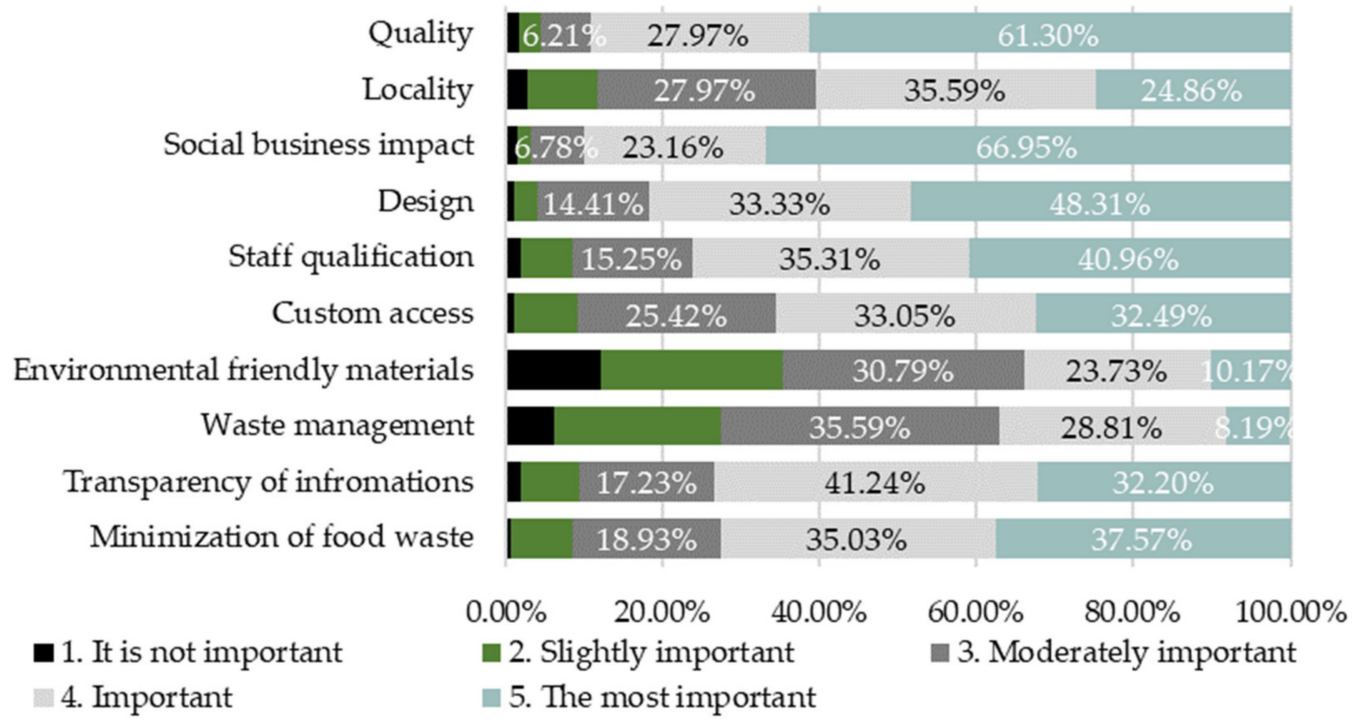

Figure 5. Graph of perceived importance of individual parameters of value on a scale of 1-5 according to customers.

\subsubsection{Customer Perception of Global Problems}

The following graph (Figure 6) shows the answers to the questions aimed at determining the perception of global problems. Respondents chose from the options "yes, no, I don't know", while the questions were aimed at finding out their awareness of the problem. In the first case, it is an environmental question: "Do you perceive problems such as global warming, the amount of non-recycled waste, or air pollution as a problem that affects you personally?" In this regard, the survey focused on the environmental environment. Almost $86 \%$ of respondents perceive global environmental problems. The figure shows several answers in one graph, while it is possible to observe that the answer yes is above $69 \%$ in all answers. Thus, consumers clearly perceive global problems as a topic that should be actively addressed. They believe that buying them as an individual can affect market supply, so that if they change their shopping behavior, they can influence the consumer offer and thus promote sustainable products and services. They correspond in percentages to $69.21 \%$ of all respondents preferring environmentally friendly companies and up to $74.86 \%$ of all respondents knowing brands in their neighborhood that implement a sustainable approach to their business.

Respondents answered positively on environmental sustainability issues in more than $70 \%$ of cases (Table 5). All positive responses to business sustainability exceeded $70 \%$. Within the given article, we state the highest and lowest range of answers.

As many as $63 \%$ of respondents from the customer survey perceive the problems of the natural environment and at the same time believe that they can influence the market offer with their purchases and thus contribute to a more sustainable environment. Verification of the dependence of this relationship was treated by a chi-square test, with a $p$-value of 18.59 with a significance of 0.001 . Based on this conclusion, it is possible to assess that the relationship is statistically significant. 


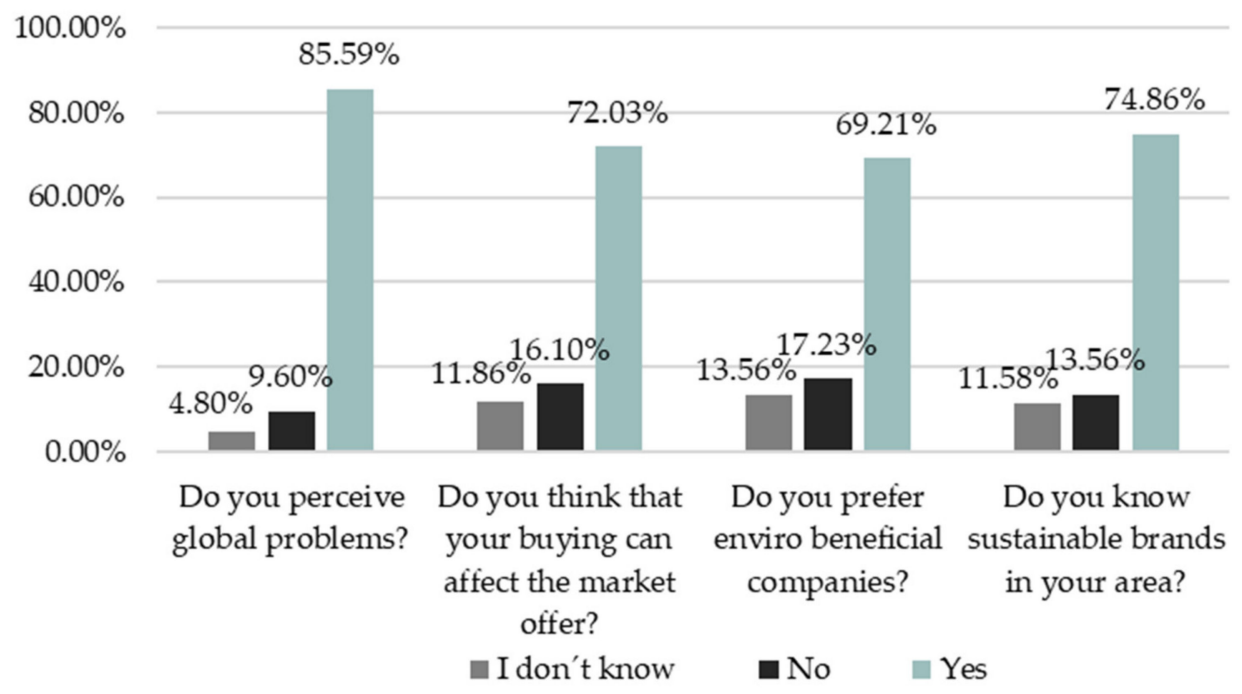

Figure 6. Evaluation of interest in societal issues in the field of sustainability.

Table 5. Percentage of answers to "global perception" and "belief in change through sustainable purchasing".

\begin{tabular}{ccccc}
\hline \multirow{2}{*}{ Numbers within the Questions } & \multicolumn{2}{c}{ Belief in Changing the Market Offer by Own Purchases } \\
\cline { 3 - 5 } & & Yes & No & I Don't Know \\
\hline Perception of global & Yes & $62.99 \%$ & $11.58 \%$ & $11.02 \%$ \\
environmental & No & $5.08 \%$ & $3.95 \%$ & $0.56 \%$ \\
problems & I don't know & $3.95 \%$ & $0.56 \%$ & $0.28 \%$ \\
\hline
\end{tabular}

\subsection{Hypothesis Verification}

Companies perceive their own value as a way of fulfilling their business goals, which in most companies are presented by the products themselves. In the field of micro and small enterprises, the main motivating element for establishing a business model is its very value-solving the personal values of the founding leader, in $95 \%$ of business owners (research of perceived sustainability in micro and small enterprises in Slovakia). The identified parameters of the perceived value of sustainability from the point of view of entrepreneurs were subsequently verified by primary research, but also by secondary data through foreign research and case studies, which support the logic of dividing parameters into areas or the nature of stakeholders in value management in terms of sustainability.

Hypothesis 1 (H1): In the pre-research part, the first interviews were conducted with entrepreneurs in order to understand their perception of value. In many cases, entrepreneurs could not define exactly what their value was without being explained in more detail than how to look at the value as such. After clarifying that this is a value as an internal stimulus for the establishment of the main idea of a business idea and elements that are superior to economic results, the responses were more prompt, more accurate, and the certainty in the given answer increased. The level of knowledge also increased through the interview itself. This consideration forced the entrepreneur to think about the deeper idea of the whole business.

The data described in more detail are in the pre-research section, how the research was conducted and what the reactions of entrepreneurs were. After jointly determining the individual parameters, the entrepreneurs were able to precisely define the values, as well as the scope of their application and the positive effects of such solutions. Most of the respondents from the pre-research after the interview stated that they are satisfied that they participated in the interviews and perceive that this type of interview was of an educational nature for them, and they would like to learn more about the issue and results. The tendency to address issues of value management and sustainability was also 
confirmed in the case of respondents in the main research-research on the perception of sustainability values in Slovak companies. After the first survey, entrepreneurs showed interest in the subsequent implementation of sustainability parameters into their business models. However, the most significant interest was recorded in the segment of gastronomic companies, where, for the four examined parameters of sustainability, $65 \%$ of respondents plan to implement parameters after the research aimed at prioritizing local suppliers and minimizing waste, and up to $76.19 \%$ of plan focusing on purchasing from sustainable sources and $55 \%$ of respondents plan to implement waste management. In the service and production segments, the motivation for the implementation of elements is not so strong for all elements. In the service segment, $73 \%$ plan to implement innovations in the local supply chain, and in the case of production it is also $73 \%$ of respondents. In purchasing from sustainable sources, it is $78 \%$ service sector and $80 \%$ for production. However, in the other two elements, only $43 \%$ of entrepreneurs involved in research from the services segment mentioned the planned innovation activities, only $32 \%$ from the waste management production segment, and $43 \%$ in waste minimization.

Based on the given data, the validity of the hypothesis is confirmed. Due to the differences in parameters and segments it is argued that the average values in all examined parameters are higher, more than half of the respondents plan innovations in the field of sustainability within their business model.

Hypothesis 2 (H2): The parameters of the perceived values were tested and adjusted because of the primary and secondary data so that their formulation was clear and understandable. Subsequently, the parameters were tested in research focused on the perception of sustainability values in micro and small enterprises in Slovakia. From the data obtained in the primary research, the statistical significance of the dependence of the waste minimization parameter was confirmed in connection with the company perceiving the parameter as important, i.e., he chose option 4 or 5 on the scale of importance $1-5$, so at the same time he applies it to his business model in $92.5 \%$ of cases. This speech also answers the part of the research question, which focused on the transfer of personal values to other parts of life, e.g., business.

Specific research question: Assign a level of importance to your perceived elements of sustainability. The importance was determined on a scale from 1 to 5 , where 1 is the least important and 5 is the most important. In the parameter "waste minimization", $92.5 \%$ of companies indicated an importance level of 4 (important) to 5 (most important) and at the same time in the question of whether they implement the given parameter in their business model they marked it as yes. Based on statistical significance, H2 is confirmed (Table 6).

Table 6. Verification of $\mathrm{H} 2$.

\begin{tabular}{ccc}
\hline $\begin{array}{c}\text { Perceived Importance of the Parameter } \\
\text { by Entrepreneurs }\end{array}$ & $\chi^{2}$ Test & $\begin{array}{c}\text { Application of the Parameter to } \\
\text { the Business Model }\end{array}$ \\
\hline $\begin{array}{c}\text { Waste minimization (energy, material, } \\
\text { products, time, etc.) }\end{array}$ & $\chi^{2}$ & 10.086 \\
& $\begin{array}{c}p \text {-value } \\
\text { Significance }\end{array}$ & 0.018 \\
yes
\end{tabular}

Hypothesis 3 (H3): The researched hypothesis is part of a customer survey. In the survey, however, it is possible to preliminarily evaluate the relationships between the questions, "Do you perceive it as necessary for society to become interested in global issues such as the amount of waste, air, and water pollution, or global warming? Indicate on a scale of 1 to 5 the seriousness of this issue, 1 indicating that this issue is not important for the company and 5 that it is necessary for the company to start actively addressing this issue." As well as the question, Do you prefer companies that try to be environmentally friendly? Beneficial? (They practice activities such as separation, recycling, actively seek sustainable alternatives for materials, supply routes, etc.). 
The method of hypothesis testing was used to determine statistical significance between the examined questions with a $p$-value of less than 0.001 and thus the result is statistically significant and $\mathrm{H} 3$ was confirmed. As $76.71 \%$ of respondents perceive it as necessary to solve global problems, they really prefer environmentally friendly companies (Table 7).

Table 7. Verification of H3.

\begin{tabular}{lcc}
\hline & $\chi^{2}$ Test & Prioritizing the Environmentally Friendly Companies \\
\hline Do you see it as necessary for society & $\chi^{2}$ & 37.488 \\
to become interested in global issues? & $p$-value & $<0.001$ \\
& Significance & yes \\
\hline
\end{tabular}

\subsection{Proposal of Optimization Steps for Entrepreneurs}

Based on research on the Slovak market, it is possible to assess that the level of perception of the issue in the business environment is very high. Businesses perceive the importance of sustainability and its parameters for the functioning of their businesses. Consumer interest in this topic has also been confirmed. Businesses therefore have an environment that is ready for change towards a greener approach to business. The first step, namely the awareness of the importance of the issue is already taken in society and thus companies can move to the phase of implementing innovations leading to greener and more sustainable solutions. It is important to set a baseline and name the parameters that the company aims to optimize and change to more sustainable. In the first phase, these are gradual changes that should bring the company to sustainability. However, it is essential that entrepreneurs realize that environmental sustainability is a process. It is a never-ending activity aimed at optimizing and constantly searching for more environmentally friendly solutions. Based on the research, we will further research the design of a minimalist model for managing the parameters of environmental sustainability applicable in the environment of small and micro businesses.

\section{Discussion}

The necessity of dealing with the issues of sustainability is globally known. It is supported by the results of studies performed by numerous scientists and by the facts implying an imminent climate crisis [18-20]. The market and its requirements are changing as well. Customers begin to ask about the origin of products, means of production and distribution, and suppliers are gradually being forced to react to these questions.

The consumerist way of life brought numerous business models mainly focused on the amount of production and the product's price for the final customer. However, customers' requirements are changing, and the price loses its position as the main and sole element of interest of the customers in the process of purchasing [21]. This model of oversaturation of the market by products and services has caused customers to start showing a deeper interest in the products, trying to find the right one in the abundance of the products available. The studies show that customers are often confused. Businesses have reacted to the changes in the market and applied several innovations within the edification of a more ecological way of life. However, in most of the cases, the changes were merely marketing ones, leaving the products themselves unchanged. This is the case of changing the packaging, products' descriptions, or emphasizing the ecological elements applied in the production and distribution of the products and services. These changes cannot be truly declared and proven. There are several symbols for a specific way of recycling the packaging or for the declaration of an ecological content, and so on. However, most of these symbols are not unified and each brand created its own versions.

The main step in the innovation process in the field of sustainability are made by the authorities. They try to communicate social goals and point out in a measurable way steps to improve the situation in society. It is important to realize that most of these steps, 
however, are very narrowly specified around business in the segment of medium and large companies. Thus, there is a marked absence of simple communication of sustainable parameters in practice. For this reason, we decided to prepare a simple form of summary of the main parameters of sustainability in the field of small and micro enterprises. Finding opportunities for unified communication of the issue to the public is a difficult process. However, customers perceive the issue as a serious aspect that entrepreneurs should address and adapt their business to. According to research in companies, the perception of the issue of waste minimization is evident especially in business segments, where these are products of immediate consumption. So, the most significant steps in the direction of eco-innovation are applied in the field of gastronomy (restaurants, cafes, cafeterias, etc.). The lowest level of awareness and interest was recorded in the field of services, especially in the field of construction.

Our proposed value management model of value parameters to support sustainability in micro and small enterprises is an exact list of parameters and their areas, which the company can analyze before their implementation, during implementation and evaluate after implementation. It is a system of looking at the issue across the area of stakeholders through the optics of the value parameter.

The design and function of the model are subject to lean management methodologies. This is an approach with the utmost effort to avoid waste. The specifics of the model are its simplicity, clarity, avoidance of supply and emphasis on linking all processes to the customer and the environment, and thus increasing trust between all stakeholders.

After the overall evaluation of the model verification, the ambition is to bring to the research results a supplemented part describing the proposed alternative solutions to the individual sustainability parameters. They would serve as a quick aid in finding solutions to the so-called "better options" in terms of value parameters implemented in the company. This fact is essential in realizing that sustainability and its application to the business environment has its phases. These phases begin with the initial awareness of small changes to promote sustainability. Gradually, after they are automated into the company's activities, it is possible to move to the next level (ideally with another balance period, then new goals, and the next level of the model).

Due to the lean approach of the whole methodology, the setting of a new level is given based on the parameters of lean management:

- Simplicity,

- Clarity,

- Targeting.

After applying these specifics, the company will be able to set new goals and improve the original parameters of the model. The model provides an agile methodology for managing value parameters to support sustainability in micro and small businesses.

Verification of model parameters from the point of view of the external environment is a necessary indicator of the correct definition of parameters and their importance for customers. The parameters of sustainability value represent specific areas for improvement in the sustainable goals of the company itself, but also in the general goals of the company. The need for retrospective review from an external environment serves as a verification parameter for possible adjustment and prioritization of individual parameters and the model itself.

The FOCUS agency and the Business Leaders Forum carried out a survey, the main goal of which was to analyze trends in the perception of responsible business in the Slovak market from the perspective of the public. The survey was conducted in Slovakia, it is a survey of the public and its perception of a responsible approach to business, it was conducted in October 2019. The survey was conducted in the form of a questionnaire on a representative sample of 1021 respondents aged 18 years.

As many as $94 \%$ of respondents think that companies should, in addition to making a profit, also have priority in their CSR goals and up to $91 \%$ of respondents think that companies should inform the public about their CSR activities. For the question of examining the 
consumer's knowledge of what CSR really is, 25\% agreed that CSR is honest in business, $25 \%$ perceive CSR as environmental consideration in their business, and $25 \%$ perceive CSR as non-abuse of employees, the remaining $25 \%$ were different types of responses.

When asked whether the respondents can spontaneously state at least one company that does business responsibly, up to $48 \%$ of respondents answered yes and mentioned Slovak companies such as Lidl Slovakia (13\%), Orange, Slovakia (10\%), Telekom (9\%), Kaufland Slovak Republic (8\%), and Tesco STORES SR (8\%). When asked about societal issues that companies should address, 53\% mentioned the environment and climate change [22].

The Datank agency prepared a survey of hundreds of companies in Slovakia for ČSOB. These are companies from the small and medium segments. The results of the survey were published in 2020, and their results are interesting conclusions on the topic.

The aim of the survey was questions focused on eco-innovations applied to business models of entrepreneurs. Almost a third of companies (31\%) have already implemented some of the activities aimed at reducing their negative impact on the environment. However, a much more favorable number came out in the question: "Are you implementing such measures now?" Up to $46 \%$ of Slovak companies in the field of SMEs are in this stage of eco-innovation implementation. One fifth of respondents (18\%) stated that they do not introduce eco-innovation and do not plan to do so in the future [23]. "Protecting the environment is my life credo and I also subordinate the functioning of the company to it" said Marian Pánik, Profi Building Materials, in the survey. An interesting specificity of the surveyed subjects is that the larger the company, the more its interest in environmentally beneficial activity increases. More than two fifths of companies (42\%) are motivated by social responsibility for eco-innovation, and almost one third of respondents simply consider it correct and natural. Roughly $16 \%$ of companies have the introduction of ecological processes and innovations ordered by legislation. "When we asked companies why they did not implement environmental measures, they most often said that they did not have a chance to affect the environment as part of their business activities. The highest representation among these companies was around wholesale, retail, repairs, and maintenance, as well as administration" explains Dáša Polláková, manager of the Department for Small and Medium-sized Enterprises of ČSOB. Regardless of the size of the company, the most common measure is the recycling of waste, which has been actively mastered by more than a third of respondents (36\%) and $17 \%$ of entrepreneurs reach for energy-saving electrical appliances. Roughly $15 \%$ of companies use new ecological materials or ecological packaging materials in their production and $8 \%$ of entrepreneurs work with ecological technologies [23].

A greener approach to business also means higher innovation costs for some segments. Most companies involved (70\%) in the survey stated that they did not include the additional costs involved in the final prices. "Of course, in this case, the decisive factor is in which segment/sector the company operates and for which type of measure it has decided. On average, 7 out of 100 entrepreneurs contacted include these costs in the value of a product or service, and another almost $1 / 4$ of companies partially reflects the costs of eco-innovation in the price of products and services," adds Polláková [23].

The resources needed for eco-innovation are common reasons that entrepreneurs consider when operating greener. Almost one third of companies are reluctant to be ecological precisely because of the financial demands of investments in environmental protection. Another $14 \%$ of entrepreneurs are bound by legislation, $6 \%$ of companies complain about the lack of experts, 5\% of entrepreneurs lack demand from clients, and 17\% of companies operate in a segment that does not allow environmental measures. Skepticism is the main reason for $2 \%$ of respondents [23].

The level of awareness of the issue is high in the business environment. In the monitored segments, the most significant results were in the gastro segment, which also has the highest degree of motivation to implement innovations in the future. To shift the awareness of entrepreneurs, it is necessary to set the main measures for setting measurable goals in the field of sustainability. This is the exact naming of parameters and their measurable units. It 
is necessary to record the baseline so that these steps can be subsequently optimized and evaluated. Sustainability is a never-ending process of growth in corporate culture and the natural environment.

Customer perception of the issue is also at a very high level. At the same time, customers feel responsible for the impact of consumer purchasing and believe that sustainable approaches to consumption tend to change market supply (62\% of respondents in customer surveys). For companies and customers, it is first and foremost necessary to start communicating the individual steps towards sustainability. Given the results of research, it is evident that companies are trying to be more sustainable, as well as that customers are looking for sustainable businesses. Therefore, it is essential that companies start communicating these steps at any stage of the solution. It is essential that customers learn about this activity and thus have the opportunity to support their innovation.

\section{Conclusions}

The changes related to the perception of sustainability described in this article are especially reflected in the behavior of millennials. Young people can make their way around the abundance of information present in the online or offline environment. They have grown up in a time when the accessibility of products and services reached the level of demand; thus they mostly do not know the feeling of shortage of something [24] However, their preferences include values such as environmental sustainability, ecological help, or engagement in social issues. They have their own attitude towards global problems and the solution to the imminent climate crisis. This perspective determines the next generation of consumers, and the elements of their behavior should be applied in the business environment. Businesses can be more intriguing and preferred to their competitors if they declare a value system based on ecological principles [25].

The issues of environmental sustainability represent a well-known topic for corporations which is being actively approached via the implementation of CSR principles into the companies' operation [26]. However, these models are very complicated, and it is often impossible to implement them in micro and small businesses. Therefore, this research focused on this environment. The results show that the level of importance of the elements of environmental sustainability in Slovakia is high. A substantial finding for further research is also the fact that local businesses are planning to broaden their knowledge in this field, and they are willing to innovate. For this reason, it is substantial to bring new pieces of knowledge not only for the science but also for micro and small businesses, representing a considerable part of the Slovak business environment. These entrepreneurs are able to support the economy even during a crisis since they are able to swiftly react to the changes in the market. The design of a model of environmental sustainability for micro and small businesses will help them with a smooth adaptation to new changes, contributing to the European goals for a greener world [27-29].

The aim of this article was to provide a general view of the changing perception of values in relation to sustainability. Consumers are changing their behavior and, given the level of entrepreneurs' belief in eco-innovation, we consider data on customer demand specifications to be crucial. At the same time, however, we perceive it as necessary to bring comprehensible solutions applicable to the common practice of micro and small entrepreneurs in Slovakia.

Questionnaire research of consumers reflected the significant importance of solving the problem and confirmed the research hypotheses of the article. Consumers prefer businesses that actively address environmental issues and strive to do business sustainably. The supporting surveys in the discussion section confirm our claims with secondary data. Based on our analyses, we perceive this issue as significantly important for building values in the field of micro and small businesses, not only in the Slovak business market.

Author Contributions: Conceptualization, M.D. and M.V.; methodology, M.D. and M.V.; software, M.D.; validation, M.D.; formal analysis, M.D and M.V.; investigation, M.D.; resources, M.D.; data curation, M.D.; writing — original draft preparation, M.D.; writing—review and editing, M.D.; visual- 
ization, M.D.; supervision, M.V.; project administration, M.D. and M.V.; funding acquisition, M.D. and M.V. Both authors have read and agreed to the published version of the manuscript.

Funding: This research was funded by the Grant System of University of Zilina No. 1/2020, grant number 7941 and VEGA 1/0533/20 Online Reputation Management: Tools and Methods.

Institutional Review Board Statement: Not applicable.

Informed Consent Statement: Not applicable.

Data Availability Statement: Not applicable.

Conflicts of Interest: The authors declare no conflict of interest.

\section{References}

1. Demjanovičová, M. Current Situation in the Field of Management of the Value of Small and Medium-Sized Enterprises through Marketing Activities; Sciemcee Publishing: London, UK, 2018; pp. 51-53. ISBN 978-0-9935191-7-8.

2. Del Borghi, A.; Gallo, M.; Strazza, C. An evaluation of environmental sustainability in the food industry through Life Cycle Assessment: The case study of tomato products supply chain. J. Clean. Prod. 2014, 78, 121-130. [CrossRef]

3. Ranta, V.; Aarikka-Stenroos, L.; Mäkinen, S.J. Creating value in the circular economy: A structured multiple-case analysis of business models. J. Clean. Prod. 2018, 201, 988-1000. [CrossRef]

4. Kim, A.J.; Ko, E. Do social media marketing activities enhance customer equity? An empirical study of luxury fashion brand. J. Bus. Res. 2012, 65, 1480-1486. [CrossRef]

5. Strand, R. Strategic Leadership of Corporate Sustainability. J. Bus. Ethic 2014, 123, 687-706. [CrossRef]

6. Strand, R. The Stakeholder Dashboard. Greener Manag. Int. 2006, 2006, 23-36. [CrossRef]

7. Schaltegger, S.; Hansen, E.G.; Lüdeke-Freund, F. Business models for sustainability: Origins, present research, and future avenues. Organ. Environ. 2016, 29, 3-10. [CrossRef]

8. Chernev, A.; Blair, S. Doing Well by Doing Good: The Benevolent Halo of Corporate Social Responsibility. J. Consum. Res. 2015, 41, 1412-1425. [CrossRef]

9. Collins, J. Good to Great; Eastone Books Publishing: Bratislava, Slovakia, 2005; ISBN 80-89217-09-5.

10. Demjanovičová, M.; Varmus, M. Knowing the Parameters of Perceived Value in the Companies Operating in Smart Environment. CER-Comparative European Research 2019. In Proceedings of the 12th Biannual, London, UK, 28-30 October 2019; Sciemcee Publishing: London, UK, 2019; pp. 56-59. ISBN 978-1-9993071-5-8.

11. Dankova, A.; Droppa, M. The Impact of National Culture on Working Style of Slovak Managers. Procedia Econ. Finance 2015, 34, 164-171. [CrossRef]

12. Dentoni, D.; Pinkse, J.; Lubberink, R. Linking Sustainable Business Models to Socio-Ecological Resilience Through Cross-Sector Partnerships: A Complex Adaptive Systems View. Bus. Soc. 2020. [CrossRef]

13. Finstat.sk. Statistics about Companies in Slovak Business Area. 6.8.2020. Available online: https://finstat.sk/databaza-firiemorganizacii (accessed on 10 January 2021).

14. Demjanovičová, M. The impact of value on the effectiveness of marketing communication of local companies. Edukacja Ekonomistów i Menedżerów 2020, 55, 24-32. [CrossRef]

15. Abahumna, A. Sustainability of small and micro enterprises. Int. J. Curr. Res. 2019, 11, 5175-5179. [CrossRef]

16. Condon, L. Sustainability and Small to Medium Sized Enterprises-How to Engage Them. Aust. J. Environ. Educ. 2004, 20, 57-67. [CrossRef]

17. Hrušovská, D.; Demjanovičová, M.; Mičiak, M.; Tumová, D. Analysis of the perception of sustainability from the perspective of entrepreneurs and consumers in the food industry in Slovakia. In Proceedings of the 35th IBIMA Conference, Seville, Spain, 1-2 April 2020; ISBN 978-0-9998551-4-0.

18. Zrakova, D.; Kubina, M.; Koman, G. Influence of information-communication system to reputation management of a compa-ny. In Proceedings of the 12th International Scientific Conference of Young Scientists on Sustainable, Modern and Safe Transport, High Tatras, Slovakia, 31 May-2 June 2017; Volume 19, pp. 100-1000.

19. Newman, G.E.; Gorlin, M.; Dhar, R. When Going Green Backfires: How Firm Intentions Shape the Evaluation of Socially Beneficial Product Enhancements. J. Consum. Res. 2014, 41, 823-839. [CrossRef]

20. Van Hille, I.; De Bakker, F.G.A.; Groenewegen, P.; Ferguson, J.E. Strategizing Nature in Cross-Sector Partnerships: Can Plantation Revitalization Enable Living Wages? Organ. Environ. 2019. [CrossRef]

21. L'Observatoire Cetelem. Consumption in Europe: New Paths to Confidence. 2017. Available online: https://www.cetelem.sk/ospolocnosti/aktuality/prieskum-spokojnosti-zakaznikov /Contents/0/observatoire_conso_2017_gb_ss_annexes_bd.pdf (accessed on 13 January 2021).

22. Blf.sk. Research FOCUS for BLF: Slováci Chcú, aby Firmy Bojovali Proti Klimatickej Zmene a Korupcii. Business Leaders Forum. 2019. Available online: http:/ / www.blf.sk/aktuality-partnerov/slovaci-chcu-aby-firmy-bojovali-proti-klimatickej-zmene-akorupcii/ (accessed on 14 January 2021). 
23. Forbes.sk. Tretina Slovenských Firiem Zaviedla Ekoinovácie. Odrazí sa to na Zvýšení Cien za Služby i Tovar, TASR. 2020. Available online: https: / www.forbes.sk/tretina-slovenskych-firiem-zaviedla-ekoinovacie-odrazi-sa-to-na-zvyseni-cien-zasluzby-i-tovar/ (accessed on 14 January 2021).

24. Zaman, M.; Yamin, S.; Wong, F. Environmental Consumerism and Buying Preference for Green Products. In Proceedings of the Australian Marketing Educators' Conference, Adelaide, Australia, 11-16 February 1996; pp. 613-626.

25. Servaes, H.; Tamayo, A. The Impact of Corporate Social Responsibility on Firm Value: The Role of Customer Awareness. Manag. Sci. 2013, 59, 1045-1061. [CrossRef]

26. Straková, J.; Pártlová, P.; Váchal, J.; Vochozka, M. Excellent top manager system (ETMS)—Quality management tool tertiary education. In Proceedings of the 29th International Business Information Management Association Conference-Education Excellence and Innovation Management through Vision 2020, Milan, Italy, 4-5 May 2016; pp. 1844-1852.

27. Rohrbeck, R.; Konnertz, L.; Knab, S. Collaborative business modelling for systemic and sustainability innovations. Int. J. Technol. Manag. 2013, 63, 4-23. [CrossRef]

28. Naderi, I.; Van Steenburg, E. Me first, then the environment: Young Millennials as green consumers. Young Consum. 2018, 19, 280-295. [CrossRef]

29. World Economic Forum, Engaging Tomorrow's, Industry Agenda. 2013. Available online: http://www3.weforum.org/docs/ WEF_RC_EngagingTomorrowsConsumer_Report_2013.pdf (accessed on 9 January 2021). 